\title{
Produtividade de arroz irrigado e eficiência de uso do nitrogênio influenciadas pela fertilização nitrogenada
}

\author{
Nand Kumar Fageria ${ }^{(1)}$, Alberto Baêta dos Santos ${ }^{(1)}$ e Veridiano dos Anjos Cutrim ${ }^{(1)}$ \\ (1)Embrapa Arroz e Feijão, Rod. GO 462, Km 12, Zona Rural, Caixa Postal 179, CEP 75375-000 Santo Antônio de Goiás, GO. \\ E-mail: fageria@cnpaf.embrapa.br, baeta@cnpaf.embrapa.br, cutrim@cnpaf.embrapa.br
}

\begin{abstract}
Resumo - $\mathrm{O}$ objetivo deste trabalho foi avaliar a resposta de genótipos de arroz irrigado à aplicação de nitrogênio. O experimento foi conduzido em campo, por dois anos consecutivos, com 12 genótipos e cinco doses de $\mathrm{N}$. Foram utilizadas doses de $0,50,100,150$ e $200 \mathrm{~kg} \mathrm{ha}^{-1} \mathrm{de} \mathrm{N}$. Os genótipos de arroz irrigado apresentaram diferenças significativas na produtividade de grãos. Houve resposta significativa e quadrática à aplicação de N. Nos dois anos de cultivo, os genótipos mais produtivos foram BRSGO Guará e BRS Alvorada, e os menos produtivos foram BRS Jaburu e BRS Biguá. A maior produtividade dos genótipos BRS Guará e BRS Alvorada está associada ao maior número de panículas, maior índice de colheita e menor esterilidade de espiguetas sob alta dose de $\mathrm{N}$. Os genótipos diferiram, também, na eficiência do uso de $\mathrm{N}$, no que se refere à produtividade de grãos por quilograma de $\mathrm{N}$ aplicado, $\mathrm{N}$ acumulado na planta ou recuperado pela planta.
\end{abstract}

Termos para indexação: Oryza sativa, arroz irrigado, componentes de rendimento, eficiência agronômica.

\section{Yield and nitrogen use efficiency of lowland rice genotypes as influenced by nitrogen fertilization}

\begin{abstract}
The objective of this work was to evaluate the yield of lowland rice genotypes as affected by nitrogen fertilization. A field experiment was conducted, during two consecutive years, in order to evaluate the response of 12 irrigated rice genotypes to five doses of $\mathrm{N}$ application. The $\mathrm{N}$ doses used were $0,50,100,150$ and $200 \mathrm{~kg} \mathrm{ha}^{-1}$. Genotypes differed significantly in relation to grain yield. Response of genotypes to $\mathrm{N}$ rate was significant and quadratic. Genotypes BRSGO Guará and BRS Alvorada had maximum grain yield and BRS Jaburu and BRS Biguá were the lowest yield producers, during two years of cultivation. Higher productivity of BRSGO Guará and BRS Alvorada was associated with higher panicle number, higher grain harvest index, and low grain sterility at higher $\mathrm{N}$ rates. Genotypes also differed in $\mathrm{N}$ use efficiency regarding grain produced per kilogram of $\mathrm{N}$ applied, and regarding $\mathrm{N}$ accumulated in the plant or recovered by plant
\end{abstract}

Index terms: Oryza sativa, irrigated rice, yield components, agronomic efficiency.

\section{Introdução}

A importância do nitrogênio na cultura de arroz irrigado é indiscutível. A deficiência de N nesta cultura, nos solos de várzeas do Brasil Central, é freqüentemente observada (Fageria et al., 2003a), e entre as principais razões para sua ocorrência estão as perdas por vários processos (volatilização, lixiviação, desnitrificação, erosão), baixas doses de aplicação e diminuição do teor de matéria orgânica em conseqüência dos cultivos sucessivos. É, também, o nutriente que a planta de arroz acumula em maior quantidade, com exceção do $\mathrm{K}$ (Fageria et al., 2003b).

$\mathrm{O}$ arroz no Brasil é cultivado em várzeas e terras altas, sob diversos sistemas de produção. A cultura de arroz irrigado contribui com aproximadamente $68 \%$ da produção brasileira e ocupa cerca de $31 \%$ da área cultivada com este cereal. No Brasil, existem aproximadamente 35 milhões de hectares de várzeas e, no momento, menos de 2 milhões de hectares desse total são utilizados na produção de arroz irrigado. A maioria das áreas de várzeas está localizada nas margens de rios ou lagos e, em muitas delas, há disponibilidade de água durante a época da seca, o que possibilita o cultivo de outra espécie pelo uso da subirrigação. Isso significa que existe grande potencial para aumentar as áreas de várzeas para a produção de grãos no país. A maioria dos solos de várzeas, contudo, são ácidos e, após dois ou três cultivos, têm sua fertilidade diminuída significativamente (Vahl, 1999). Isto é particularmente 
importante para o $\mathrm{N}$, principalmente em sistemas irrigados, pelo seu envolvimento nas reações de nitrificação e desnitrificação.

A eficiência de recuperação de $\mathrm{N}$ pelo arroz inundado situa-se em torno de $40 \%$, em solo de várzea (Fageria \& Baligar, 2001). Nessa situação, o uso racional da adubação nitrogenada é fundamental, não somente para aumentar a eficiência de recuperação, mas também para aumentar a produtividade das culturas e diminuir o custo de produção e os riscos de poluição ambiental. A eficiência de recuperação de $\mathrm{N}$ pode ser aumentada com a adoção de práticas de manejo apropriadas, como o uso de dose adequada e aplicação na época apropriada, de acordo com resultados de pesquisa e com a necessidade da cultura (Fageria et al., 2003b). Além disso, o emprego de cultivares eficientes na absorção e utilização de $\mathrm{N}$ é uma importante estratégia para aumentar a eficiência de seu uso. A literatura indica que existe grande diferença entre as cultivares quanto à capacidade de absorção e utilização de nutrientes, inclusive N (Singh et al., 1998).

O objetivo deste trabalho foi avaliar respostas de genótipos de arroz irrigado à aplicação de nitrogênio.

\section{Material e Métodos}

O experimento foi conduzido na Fazenda Palmital, da Embrapa Arroz e Feijão, durante dois anos consecutivos nas safras de 2003/2004 e 2004/2005, num Gleissolo Háplico distrófico de várzea (Embrapa, 1999). Os resultados da análise química e granulométrica das amostras de solo da área experimental, coletadas antes da instalação do experimento, revelaram: $\mathrm{pH} 4,8 ; \mathrm{MO}, 9 \mathrm{~g} \mathrm{dm}^{-3}$; $\mathrm{P}$, $24,5 \mathrm{mg} \mathrm{dm}^{-3} ; \mathrm{K}, 34 \mathrm{mg} \mathrm{dm}^{-3} ; \mathrm{Ca}, 1 \mathrm{cmol}_{\mathrm{c}} \mathrm{dm}^{-3} ; \mathrm{Mg}$, $0,5 \mathrm{cmol}_{\mathrm{C}} \mathrm{dm}^{-3} ; \mathrm{Al}, 1,5 \mathrm{cmol}_{\mathrm{c}} \mathrm{dm}^{-3} ; \mathrm{Cu}, 5,1 \mathrm{mg} \mathrm{dm}^{-3} ; \mathrm{Zn}$, $4,9 \mathrm{mg} \mathrm{dm}^{-3}$; Fe, $462 \mathrm{mg} \mathrm{dm}^{-3}$ e $\mathrm{Mn}, 14 \mathrm{mg} \mathrm{dm}^{-3}$. A análise granulométrica mostrou $322 \mathrm{~g} \mathrm{dm}^{-3} \mathrm{de}$ argila, $140 \mathrm{~g} \mathrm{dm}^{-3}$ de silte e $538 \mathrm{~g} \mathrm{dm}^{-3} \mathrm{de}$ areia. As análises química e granulométrica de solo foram realizadas de acordo com o manual e métodos de análise do solo da Embrapa (1997).

A dose de calcário foi calculada com base no teor de $\mathrm{Al}$ e $\mathrm{Ca}+\mathrm{Mg}$ trocáveis pela seguinte fórmula: dose de calcário $\left(\mathrm{Mg} \mathrm{ha}^{-1}\right)=\left(2 \times \mathrm{Al}^{3+}\right)+\left\{2-\left(\mathrm{Ca}^{2+}+\mathrm{Mg}^{2+}\right)\right\}$, corrigindose o PRNT do calcário para $100 \%$. Foram incorporados ao solo, com grade, $4 \mathrm{Mg} \mathrm{ha}^{-1}$ de calcário dolomítico, quatro semanas antes do plantio do primeiro cultivo de arroz. O calcário utilizado possuía PRNT $85,1 \%, \mathrm{CaO}, 32,9 \%$ e $\mathrm{MgO}, 14 \%$.
Os tratamentos consistiram de 12 genótipos de arroz irrigado: BRS Jaçanã, CNAi 8860, BRS Fronteira, CNAi 8879, CNAi 8880, CNAi 8886, CNAi 8885, CNAi 8569, BRSGO Guará, BRS Alvorada, BRS Jaburu e BRS Biguá, e cinco doses de N: 0, 50, 100, 150, e $200 \mathrm{~kg} \mathrm{ha}^{-1}$. A metade do $\mathrm{N}$ foi aplicada no sulco do plantio na forma de uréia, e o restante em cobertura, aos 45 dias após o plantio, também com uréia. $\mathrm{O}$ parcelamento do $\mathrm{N}$ foi baseado no trabalho de Fageria et al. (2003b). A adubação foi de $120 \mathrm{~kg} \mathrm{ha}^{-1} \mathrm{de}_{2} \mathrm{O}_{5}$ e $120 \mathrm{~kg} \mathrm{ha}^{-1} \mathrm{de}_{2} \mathrm{O}$ no sulco de plantio, tendo-se como fonte o superfosfato triplo e o cloreto de potássio.

O delineamento experimental foi o de blocos ao acaso, com parcelas subdivididas e com três repetições. As doses de $\mathrm{N}$ constituíram a parcela principal, e os genótipos as subparcelas. As parcelas foram compostas por quatro fileiras de cada genótipo com $5 \mathrm{~m}$ de comprimento. $\mathrm{O}$ espaçamento entre fileiras foi de $20 \mathrm{~cm}$. A densidade de sementes foi de 90 sementes por metro. Após 25 dias de germinação, as parcelas foram inundadas com lâmina de água de aproximadamente $10 \mathrm{~cm}$. Foi aplicado o herbicida Ronstar pré-emergência, para controlar planta daninhas.

Para a determinar a produção de grãos, foram coletadas duas fileiras centrais de $4 \mathrm{~m}$ cada, tendo-se deixado $0,5 \mathrm{~m}$ nos dois lados, como bordadura. Os genótipos foram colhidos no estádio de maturação fisiológica e, na mesma época, foi colhido um metro da linha de plantio, em cada unidade experimental, para se determinar o acúmulo de matéria seca da parte aérea. Foi determinado o número de panículas por metro, em três locais, em cada parcela.

Para a avaliação da eficiência do uso de $\mathrm{N}$, determinou-se, pelo método Kjeldahl, o N presente na parte aérea e nos grãos de cinco genótipos selecionados ao acaso. Foram realizadas as análises de variância de cada ano e a conjunta, para verificar se houve interação entre ano e genótipos. As médias dos tratamentos foram comparadas entre si pelo teste de Tukey, a 5\% de probabilidade, e foram utilizadas equações de regressão apropriadas para avaliar os efeitos da adubação nitrogenada.

Foram selecionados cinco genótipos para a realização de análises foliares, com o intuito de se reduzirem os custos. Nos genótipos selecionados, para o cálculo da eficiência do uso de $\mathrm{N}$, foram empregadas as fórmulas (Fageria et al., 2003a): eficiência agronômica $(\mathrm{EA})=\left(\mathrm{PG}_{\mathrm{cf}}-\mathrm{Pg}_{\mathrm{sf}}\right) /\left(\mathrm{QN}_{\mathrm{a}}\right)$, dada em $\mathrm{kg} \mathrm{kg}^{-1}$, em que $\mathrm{PG}_{\mathrm{cf}}$ é a produção de grãos com fertilizante nitrogenado; 
$\mathrm{PG}_{\mathrm{sf}}$ é a produção de grãos sem fertilizante nitrogenado; e $\mathrm{QN}_{\mathrm{a}}$ é a quantidade de $\mathrm{N}$ aplicado em quilograma. A eficiência fisiológica $(\mathrm{EF})=\left(\mathrm{PB}_{\mathrm{cf}}-\mathrm{PB}_{\mathrm{sf}}\right) /\left(\mathrm{AN}_{\mathrm{cf}}\right.$ $\mathrm{AN}_{\mathrm{sf}}$ ) foi dada em kg kg-1 , em que $\mathrm{PB}_{\mathrm{cf}}$ é a produção biológica (palha e grãos) com fertilizante nitrogenado; $\mathrm{PB}_{\mathrm{sf}}$ é a produção biológica (palha e grãos), sem fertilizante nitrogenado; $\mathrm{AN}_{\mathrm{cf}}$ é a acumulação de $\mathrm{N}$ na parte aérea e nos grãos, com fertilizante nitrogenado; e $\mathrm{AN}_{\mathrm{sf}}$ é a acumulação de $\mathrm{N}$ na parte aérea e nos grãos, sem fertilizante nitrogenado. A eficiência agrofisiológica $(\mathrm{EAF})=\left(\mathrm{PG}_{\mathrm{cf}}-\mathrm{PG}_{\mathrm{sf}}\right) /\left(\mathrm{AN}_{\mathrm{cf}}-\mathrm{AN}_{\mathrm{sf}}\right)$ foi dada em $\mathrm{kg} \mathrm{kg}^{-1}$, em que $\mathrm{PG}_{\mathrm{cf}}$ é a produção de grãos, com fertilizante nitrogenado; $\mathrm{PG}_{\mathrm{sf}}$ é a produção de grãos, sem fertilizante nitrogenado; $\mathrm{AN}_{\mathrm{cf}}$ é a acumulação de $\mathrm{N}$ na parte aérea e nos grãos, com fertilizante nitrogenado; e $\mathrm{AN}_{\mathrm{sf}}$ é a acumulação de $\mathrm{N}$ na parte aérea e nos grãos, sem fertilizante nitrogenado. A eficiência de recuperação $(\mathrm{ER})=100\left(\mathrm{AN}_{\mathrm{cf}}-\mathrm{AN}_{\mathrm{sf}} / \mathrm{QN}_{\mathrm{a}}\right)$ foi dada em porcentagem, em que $\mathrm{AN}_{\mathrm{cf}}$ é a acumulação de $\mathrm{N}$ na parte aérea e nos grãos, com fertilizante nitrogenado; $\mathrm{AN}_{\mathrm{sf}}$ é a acumulação de $\mathrm{N}$ na parte aérea e nos grãos, sem fertilizante nitrogenado; e $\mathrm{QN}_{\mathrm{a}}$ é a quantidade de $\mathrm{N}$ aplicado em quilograma.

O índice de colheita de grãos foi obtido pelo quociente entre produtividade de grãos $\left(\mathrm{kg} \mathrm{ha}^{-1}\right)$ e produtividade de matéria seca total da parte aérea $\left(\mathrm{kg} \mathrm{ha}^{-1}\right)$.

\section{Resultados e Discussão}

Houve efeitos significativos das doses de N, genótipos e interação entre ano e genótipos, em relação à produtividade de grãos (Tabela 1). Portanto, os dados

Tabela 1. Produtividade $\left(\mathrm{kg} \mathrm{ha}^{-1}\right)$ de genótipos de arroz irrigado. Médias de cinco doses de nitrogênio ${ }^{(1)}$.

\begin{tabular}{llll}
\hline Genótipo & 10 ano & $2 \mathrm{o}$ ano & Média \\
\hline BRS Jaçanã & $4.015 \mathrm{bc}$ & $3.663 \mathrm{ab}$ & $3.839 \mathrm{ab}$ \\
CNAi 8860 & $4.519 \mathrm{abc}$ & $4.168 \mathrm{ab}$ & $4.344 \mathrm{ab}$ \\
BRS Fronteira & $4.415 \mathrm{abc}$ & $4.372 \mathrm{ab}$ & $4.393 \mathrm{ab}$ \\
CNAi 8879 & $4.351 \mathrm{abc}$ & $4.382 \mathrm{a}$ & $4.366 \mathrm{ab}$ \\
CNAi 8880 & $4.394 \mathrm{abc}$ & $4.578 \mathrm{a}$ & $4.486 \mathrm{ab}$ \\
CNAi 8886 & $4.638 \mathrm{abc}$ & $4.262 \mathrm{ab}$ & $4.450 \mathrm{ab}$ \\
CNAi 8885 & $4.856 \mathrm{abc}$ & $4.162 \mathrm{ab}$ & $4.509 \mathrm{ab}$ \\
CNAi 8569 & $4.581 \mathrm{abc}$ & $3.565 \mathrm{ab}$ & $4.073 \mathrm{ab}$ \\
BRSGO Guará & $5.557 \mathrm{a}$ & $4.098 \mathrm{ab}$ & $4.828 \mathrm{a}$ \\
BRS Alvorada & $5.260 \mathrm{ab}$ & $4.185 \mathrm{ab}$ & $4.723 \mathrm{ab}$ \\
BRS Jaburu & $3.778 \mathrm{c}$ & $3.497 \mathrm{ab}$ & $3.638 \mathrm{~b}$ \\
BRS Biguá & $4.343 \mathrm{abc}$ & $3.252 \mathrm{~b}$ & $3.798 \mathrm{ab}$ \\
\hline Média & 4.559 & 4.015 & \\
\hline
\end{tabular}

${ }^{(1)}$ Valores seguidos por letras iguais, na mesma coluna, não diferem entre si a $5 \%$ de probabilidade, pelo teste de Tukey. dos genótipos são apresentados por ano e, com relação ao N, são apresentadas apenas as médias dos dois anos, na equação: $\mathrm{Y}=2.339,92+26,5780 \mathrm{X}-0,0474 \mathrm{X}^{2}$ $\left(\mathrm{R}^{2}=0,8900^{* *}\right)$.

A produtividade de grãos aumentou de forma quadrática, em relação às doses de $\mathrm{N}$ aplicadas. A dose de N necessária para obtenção de $90 \%$ da produtividade máxima, considerada como dose econômica, foi atendida com $136 \mathrm{~kg} \mathrm{ha}^{-1} \mathrm{de} \mathrm{N}$, que possibilitaria redimento médio de $5.077 \mathrm{~kg} \mathrm{ha}^{-1}$. Os resultados obtidos por Fageria \& Baligar (2001) mostraram que houve resposta significativa e quadrática da produtividade do arroz à aplicação de $\mathrm{N}$, na faixa de 0 a $210 \mathrm{~kg} \mathrm{ha}^{-1}$, em três anos de experimento. Tem Berge \& Riethovem (1997), ao relatar resultados obtidos na China sobre a dose adequada de $\mathrm{N}$, na produção de arroz irrigado, concluíram que, para cultivares de ciclo médio (135 dias), a dose adequada é de 100 a $150 \mathrm{~kg} \mathrm{ha}^{-1}$. Dobermann et al. (2000) relataram que a cultivar de arroz irrigado IR72 aumentou significativamente a produtividade até a dose de $150 \mathrm{~kg} \mathrm{ha}^{-1}$ de $\mathrm{N}$, em trabalho conduzido em condições de campo, no Instituto Internacional de Pesquisa de Arroz, nas Filipinas. Vahl (1999) relatou que a produtividade máxima de cultivares modernas, no Rio Grande do Sul, foi obtida com a aplicação de 114 a $126 \mathrm{~kg} \mathrm{ha}^{-1} \mathrm{de} \mathrm{N}$, dependendo da região e do solo. Mariot et al. (2003) relataram que a resposta da cultivar IRGA 417, no Rio Grande do Sul, foi linear, na faixa de 0 a $120 \mathrm{~kg} \mathrm{ha}^{-1} \mathrm{de} \mathrm{N}$, mas com a cultivar BR-IRGA 410, a resposta foi quadrática, na mesma faixa de adubação.

A produtividade de grãos entre os genótipos variou de 3.778 a $5.557 \mathrm{~kg} \mathrm{ha}^{-1}$, no primeiro ano, e de 3.252 a $4.578 \mathrm{~kg} \mathrm{ha}^{-1}$, no segundo ano de cultivo. No primeiro ano, a maior produtividade foi obtida com as cultivares BRSGO Guará, seguida pela BRS Alvorada. A cultivar BRS Jaburu apresentou a menor produtividade. No segundo ano, o genótipo CNAi 8880 apresentou a maior produtividade, seguido pelo CNAi 8879, enquanto a cultivar BRS Biguá foi a menos produtiva. Na média dos dois anos, a maior produtividade foi a da cultivar BRSGO Guará, seguida da BRS Alvorada, e a BRS Jaburu foi a menos produtiva. A BRSGO Guará produziu $33 \%$ a mais, em comparação com a BRS Jaburu. Isto significa que existe grande potencial de aumento da produtividade com a seleção de genótipos mais eficientes na absorção e utilização de N. A diferença entre os genótipos de arroz, na absorção e utilização de $\mathrm{N}$ e no potencial de produtividade, é 
largamente relatada na literatura (De Datta et al., 1988; Singh et al., 1998; Kiniry et al., 2001; Fageria et al., 2003a; Fageria \& Baligar, 2005).

O número de panículas e o índice de colheita de grãos foram influenciados significativamente pela interação ano x genótipos (Tabela 2). No primeiro ano de cultivo, o número de panículas variou de 408 a 516 panículas por metro quadrado, mas o teste de média empregado não indicou diferença significativa entre os genótipos. No segundo ano, a variação foi de 230 a 385 panículas por metro quadrado. A diminuição do estande, ocasionada pelo herbicida oxadiazon, aplicado em pré-emergência, foi a causa da redução no número de panículas, no segundo ano. As cultivares BRS Alvorada e BRSGO Guará alcançaram o maior número de panículas, e os genótipos BRS Biguá, BRS Jaçanã e CNAi 8860, o menor. Em razão do maior número de panículas, os genótipos BRSGO Guará e BRS Alvorada apresentaram maior produtividade de grãos (Tabela 1). O número de panículas foi altamente correlacionado à produtividade do arroz $\left(\mathrm{r}=0,6780^{* *}\right)$. Fageria et al. (2003b) e Fageria \& Baligar (2005) relataram que é quadrática a relação entre o número de panículas e a produtividade na cultura do arroz. Isto significa que a produtividade de arroz pode ser aumentada, com o aumento do número de panículas por unidade de área, até certo limite. O número de panículas é característica da cultivar, mas pode ser aumentado

Tabela 2. Número de panículas e índice de colheita de grãos (ICG) de genótipos de arroz irrigado. Médias de cinco doses de nitrogênio ${ }^{(1)}$

\begin{tabular}{|c|c|c|c|c|c|c|}
\hline \multirow[t]{2}{*}{ Genótipo } & \multicolumn{3}{|c|}{ Panículas por $\mathrm{m}^{-2}$} & \multicolumn{3}{|c|}{$\mathrm{ICG}^{(2)}$} \\
\hline & $1^{\mathrm{o}}$ ano & $2^{\mathrm{o}}$ ano & Média & 1으 ano & $2^{\mathrm{o}}$ ano & Média \\
\hline BRS Jaçanã & $429 a$ & $229 d$ & $329 c$ & $0,45 \mathrm{ab}$ & $0,46 \mathrm{a}$ & $0,45 \mathrm{a}$ \\
\hline CNAi 8860 & $421 \mathrm{a}$ & $242 d$ & $331 \mathrm{c}$ & $0,45 \mathrm{ab}$ & $0,48 \mathrm{a}$ & $0,47 \mathrm{a}$ \\
\hline BRS Fronteira & $423 \mathrm{a}$ & $263 \mathrm{~cd}$ & $343 b c$ & $0,43 \mathrm{ab}$ & $0,47 \mathrm{a}$ & $0,45 \mathrm{ab}$ \\
\hline CNAi 8879 & $439 a$ & $254 d$ & $346 b c$ & $0,45 \mathrm{ab}$ & $0,49 a$ & $0,47 \mathrm{a}$ \\
\hline CNAi 8880 & $454 \mathrm{a}$ & $274 \mathrm{bcd}$ & $364 a b c$ & $0,44 a b$ & $0,51 \mathrm{a}$ & $0,47 \mathrm{a}$ \\
\hline CNAi 8886 & $479 a$ & $300 \mathrm{bcd}$ & $390 \mathrm{abc}$ & $0,46 a b$ & $0,52 \mathrm{a}$ & $0,49 \mathrm{a}$ \\
\hline CNAi 8885 & $419 a$ & $339 a b$ & $379 \mathrm{abc}$ & $0,46 a b$ & $0,49 a$ & $0,48 \mathrm{a}$ \\
\hline CNAi 8569 & $413 a$ & $332 \mathrm{abc}$ & $372 a b c$ & $0,41 b$ & $0,37 \mathrm{a}$ & $0,39 b$ \\
\hline BRSGO Guará & $501 \mathrm{a}$ & $382 \mathrm{a}$ & $442 \mathrm{ab}$ & $0,51 \mathrm{a}$ & $0,48 \mathrm{a}$ & $0,49 \mathrm{a}$ \\
\hline BRS Alvorada & $516 a$ & $385 a$ & $450 \mathrm{a}$ & $0,49 \mathrm{ab}$ & $0,48 \mathrm{a}$ & $0,48 \mathrm{a}$ \\
\hline BRS Jaburu & $490 \mathrm{a}$ & $328 \mathrm{abc}$ & $409 a b c$ & $0,44 \mathrm{ab}$ & $0,46 \mathrm{a}$ & $0,45 \mathrm{a}$ \\
\hline BRS Biguá & $408 \mathrm{a}$ & $230 \mathrm{~d}$ & $319 \mathrm{c}$ & $0,48 \mathrm{ab}$ & $0,51 \mathrm{a}$ & $0,49 \mathrm{a}$ \\
\hline Média & 449 & 297 & 373 & 0,46 & 0,48 & 0,47 \\
\hline
\end{tabular}

(1)Valores seguidos por letras iguais, na mesma coluna, não diferem entre si a $5 \%$ de probabilidade, pelo teste de Tukey. (2)Índice de colheita de grãos = produtividade de grãos/produtividade de grãos mais massa de matéria seca da arte aérea. com a aplicação de dose adequada de N (Fageria \& Baligar, 2001; Fageria et al., 2006).

O índice de colheita de grãos é outro parâmetro importante na determinação da produtividade de arroz (Fageria et al., 2006). Na média dos dois anos, o índice de colheita de grãos variou de 0,39 a 0,49 (Tabela 2). Os genótipos BRSGO Guará e BRS Alvorada, que apresentaram maior produtividade de grãos, também apresentaram maior índice de colheita, em comparação aos demais genótipos. A correlação entre produtividade de grãos e índice de colheita de grãos foi significativa e positiva $\left(\mathrm{r}=0,3680^{* *}\right)$. Isso significa que esse índice está associado ao aumento da produtividade no arroz. O índice de colheita das cultivares tradicionais está em torno de 0,3 e, o das modernas, em torno de 0,5 (Mae, 1997; Fageria et al., 2006). O índice de colheita de cultivares de arroz irrigado chegou até 0,59 , em estudo conduzido na Califórnia (Roberts et al., 1993).

As interações ano x $\mathrm{N}$ e ano $\mathrm{x}$ genótipos, com relação à esterilidade de espiguetas, foram significativas. Dados relativos à esterilidade de espiguetas, nos dois anos, são apresentados na Tabela 3. Houve diferença significativa entre os genótipos, dentro de cada dose de N. Na média, houve ligeiro aumento na esterilidade de espiguetas, com o aumento da dose de $\mathrm{N}$, e este aumento variou de genótipo para genótipo. Nas cultivares BRSGO Guará e BRS Alvorada, que apresentaram as maiores produtividades, a esterilidade de grãos diminuiu com o aumento das doses de N. O genótipo BRS Alvorada mostrou mínima esterilidade de espiguetas na aplicação de $200 \mathrm{~kg} \mathrm{ha}^{-1}$ de N. A baixa esterilidade, em condição de alta dose de $\mathrm{N}$, é considerada um dos importantes critérios de seleção para as cultivares responsivas à aplicação de N (Yoshida, 1981). Em termos gerais, a maior esterilidade foi obtida no primeiro ano de cultivo. Yoshida (1981) relatou que 15\% de esterilidade de espiguetas em arroz irrigado é normal, mesmo em condições ambientais favoráveis. Alguns genótipos, como BRSGO Guará e BRS Alvorada, apresentaram valor de esterilidade em torno de $15 \%$ com a aplicação de $200 \mathrm{~kg} \mathrm{ha}^{-1}$ de $\mathrm{N}$. Esses materiais deverão ser importante fonte para o desenvolvimento de cultivares com baixa esterilidade de grãos, com o uso de altas doses de N. Esses resultados mostram que a esterilidade de grãos, em arroz irrigado, é característica dos genótipos e pode ser modificada com o uso de $\mathrm{N}$.

A massa de 1.000 grãos foi influenciada somente pelos genótipos e variou de 24,7 a 27,4 g (Tabela 4). 
Yoshida (1981) relatou que a massa de 1.000 grãos é um componente da produtividade bastante estável e característico da cultivar. A correlação entre a massa de 1.000 grãos e a produtividade de grãos foi positiva mas não significativa, o que demonstra, mais uma vez, a sua menor importância no aumento da produtividade de grãos na cultura de arroz.

Os genótipos diferiram quanto à eficiência do uso de $\mathrm{N}$ (Tabela 5). O genótipo CNAi 8886 produziu $23 \mathrm{~kg}$ de grãos por quilograma de $\mathrm{N}$ aplicado. $\mathrm{Na}$ mesma situação, o genótipo CNAi 8569 produziu $17 \mathrm{~kg}$ de grãos por quilograma de $\mathrm{N}$ aplicado. Na média, $19 \mathrm{~kg}$ de grãos foram produzidos por quilograma de $\mathrm{N}$ aplicado. Fageria \& Baligar (2001) relataram que a cultivar Metica 1 produziu $23 \mathrm{~kg}$ de grãos por quilograma de $\mathrm{N}$ aplicado. Dobermann et al. (2000) relataram que, com a aplicação

Tabela 3. Esterilidade de espiguetas de genótipos de arroz irrigado, sob diferentes doses de nitrogênio no primeiro e no segundo ano ${ }^{(1)}$.

\begin{tabular}{|c|c|c|c|c|c|}
\hline \multirow[t]{2}{*}{ Genótipo } & \multicolumn{5}{|c|}{ Doses de nitrogênio $\left(\mathrm{kg} \mathrm{ha}^{-1}\right)$} \\
\hline & 0 & 50 & 100 & 150 & 200 \\
\hline & & & $1^{\mathrm{o}}$ ano & & \\
\hline BRS Jaçanã & $13,7 \mathrm{a}$ & $17,8 \mathrm{bc}$ & $22,6 a$ & $17,2 b$ & $22,7 \mathrm{a}$ \\
\hline CNAi 8860 & $7,7 \mathrm{~b}$ & $15,9 b c$ & $17,5 \mathrm{a}$ & $18,8 \mathrm{~b}$ & $21,1 \mathrm{a}$ \\
\hline BRS Fronteira & $11,3 b$ & $20,2 b c$ & $21,1 \mathrm{a}$ & $24,6 a b$ & $23,4 \mathrm{a}$ \\
\hline CNAi 8879 & $9,9 b$ & $14,4 \mathrm{bc}$ & $18,3 \mathrm{a}$ & $19,9 \mathrm{ab}$ & $23,1 \mathrm{a}$ \\
\hline CNAi 8880 & $7,9 \mathrm{~b}$ & $14,8 \mathrm{bc}$ & $17,3 \mathrm{a}$ & $18,1 \mathrm{~b}$ & $20,3 a$ \\
\hline CNAi 8886 & $8,7 b$ & $14,3 \mathrm{bc}$ & $18,6 \mathrm{a}$ & $24,6 a b$ & $22,1 \mathrm{a}$ \\
\hline CNAi 8885 & $9,4 b$ & $11,2 \mathrm{c}$ & $15,3 \mathrm{a}$ & $16,2 b$ & $17,1 \mathrm{a}$ \\
\hline CNAi 8569 & $28,5 \mathrm{a}$ & $29,8 \mathrm{a}$ & $25,0 \mathrm{a}$ & $29,5 \mathrm{a}$ & $29,0 \mathrm{a}$ \\
\hline BRSGO Guará & $26,9 a$ & $23,3 a b$ & $16,1 \mathrm{a}$ & $19,0 \mathrm{~b}$ & $14,2 \mathrm{a}$ \\
\hline BRS Alvorada & $22,8 \mathrm{a}$ & $17,6 \mathrm{bc}$ & $14,9 \mathrm{a}$ & $15,9 b$ & $13,8 \mathrm{a}$ \\
\hline BRS Jaburu & $25,9 a$ & $21,9 a b$ & $23,7 \mathrm{a}$ & $19,8 \mathrm{ab}$ & $19,2 \mathrm{a}$ \\
\hline BRS Biguá & $23,4 \mathrm{a}$ & $17,8 \mathrm{bc}$ & $15,0 \mathrm{a}$ & $18,4 \mathrm{~b}$ & $16,6 \mathrm{a}$ \\
\hline \multirow[t]{2}{*}{ Média } & 16,3 & 18,3 & 18,8 & 20,2 & 20,2 \\
\hline & \multicolumn{5}{|c|}{ 2o ano } \\
\hline BRS Jaçanã & $9,5 b$ & $17,1 \mathrm{a}$ & $19,2 \mathrm{ab}$ & $12,4 \mathrm{a}$ & $16,2 \mathrm{ab}$ \\
\hline CNAi 8860 & $9,7 b$ & $15,4 \mathrm{a}$ & $17,5 \mathrm{ab}$ & $15,4 \mathrm{a}$ & $15,1 b$ \\
\hline BRS Fronteira & $12,4 \mathrm{~b}$ & $17,3 \mathrm{a}$ & $21,6 \mathrm{a}$ & $18,0 \mathrm{a}$ & $22,8 \mathrm{a}$ \\
\hline CNAi 8879 & $10,3 b$ & $14,0 \mathrm{a}$ & $14,9 \mathrm{ab}$ & $18,8 \mathrm{a}$ & $16,7 \mathrm{ab}$ \\
\hline CNAi 8880 & $9,5 b$ & $13,4 \mathrm{a}$ & $15,9 a b$ & $13,0 \mathrm{a}$ & $17,2 \mathrm{ab}$ \\
\hline CNAi 8886 & $12,2 b$ & $13,5 \mathrm{a}$ & $15,6 a b$ & $18,4 \mathrm{a}$ & $15,2 b$ \\
\hline CNAi 8885 & $9,9 b$ & $14,6 \mathrm{a}$ & $9,7 b$ & $15,1 \mathrm{a}$ & $15,2 b$ \\
\hline CNAi 8569 & $20,2 \mathrm{ab}$ & $15,8 \mathrm{a}$ & $15,7 \mathrm{ab}$ & $18,7 \mathrm{a}$ & $18,9 \mathrm{ab}$ \\
\hline BRSGO Guará & $26,4 \mathrm{a}$ & $20,9 \mathrm{a}$ & $21,7 \mathrm{a}$ & $17,6 \mathrm{a}$ & $16,4 \mathrm{ab}$ \\
\hline BRS Alvorada & $18,1 \mathrm{ab}$ & $15,8 \mathrm{a}$ & $17,6 a b$ & $14,1 \mathrm{a}$ & $13,4 b$ \\
\hline BRS Jaburu & $18,4 a b$ & $21,4 a$ & $15,3 a b$ & $17,6 \mathrm{a}$ & $16,1 \mathrm{ab}$ \\
\hline BRS Biguá & $19,9 \mathrm{ab}$ & $13,7 \mathrm{a}$ & $15,6 a b$ & $18,0 \mathrm{a}$ & $15,8 \mathrm{ab}$ \\
\hline Média & 14,7 & 16,1 & 16,7 & 16,4 & 16,6 \\
\hline
\end{tabular}

${ }^{(1)}$ Valores seguidos por letras iguais, na mesma coluna, em cada ano, não diferem entre si a $5 \%$ de probabilidade, pelo teste de Tukey. de $150 \mathrm{~kg} \mathrm{ha}^{-1}$ de $\mathrm{N}$, a eficiência agronômica da cultivar de arroz irrigado IR 72 foi de $20 \mathrm{~kg}$ de grãos por quilograma de $\mathrm{N}$ aplicado. Yoshida (1981) relatou que a eficiência agronômica nas regiões tropicais, geralmente, situa-se na faixa de 15 a $25 \mathrm{~kg}$ de arroz produzido por quilograma de $\mathrm{N}$ aplicado.

A eficiência fisiológica foi maior na BRSGO Guará e menor no genótipo CNAi 8886. Na média, com a acumulação de $1 \mathrm{~kg}$ de $\mathrm{N}$ na parte aérea e nos grãos, foram produzidos $155 \mathrm{~kg}$ de matéria seca (na palha e nos grãos). Fageria et al. (2003b) relataram que a acumulação de $1 \mathrm{~kg}$ de $\mathrm{N}$, na parte aérea e nos grãos, produziu $146 \mathrm{~kg}$ de matéria seca. A eficiência agrofisiológica variou de 56 a $123 \mathrm{~kg}$ de grãos produzidos por quilograma de $\mathrm{N}$ acumulado na parte aérea e nos grãos. Na média, a eficiência agrofisiológica foi de $77 \mathrm{~kg}$ de grãos por quilograma de $\mathrm{N}$ acumulado na parte aérea e nos grãos. Fageria \& Baligar (2001) relataram

Tabela 4. Massa de 1.000 grãos de genótipos de arroz irrigado. Médias de dois anos e cinco doses de nitrogênio ${ }^{(1)}$.

\begin{tabular}{lc}
\hline Genótipo & Massa de 1.000 grãos $(\mathrm{g})$ \\
\hline BRS Jaçanã & $25,3 \mathrm{bcd}$ \\
CNAi 8860 & $26,5 \mathrm{abc}$ \\
BRS Fronteira & $27,0 \mathrm{ab}$ \\
CNAi 8879 & $27,4 \mathrm{a}$ \\
CNAi 8880 & $26,6 \mathrm{abc}$ \\
CNAi 8886 & $26,7 \mathrm{abc}$ \\
CNAi 8885 & $24,7 \mathrm{~d}$ \\
CNAi 8569 & $26,0 \mathrm{abcd}$ \\
BRSGO Guará & $25,0 \mathrm{~cd}$ \\
BRS Alvorada & $26,2 \mathrm{abcd}$ \\
BRS Jaburu & $26,5 \mathrm{abc}$ \\
BRS Biguá & $26,2 \mathrm{abcd}$ \\
\hline Média & 26,2 \\
\hline (1)Valores seguidos por letras iguais, na mesma coluna, não diferem entre \\
si a 5\% de probabilidade, pelo teste de Tukey.
\end{tabular}

si a $5 \%$ de probabilidade, pelo teste de Tukey.

Tabela 5. Eficiência do uso de $\mathrm{N}$ pelos genótipos de arroz irrigado. Médias de quatro doses de nitrogênio ${ }^{(1)}$.

\begin{tabular}{lcccc}
\hline Genótipo & EA & EF & EAF & ER $(\%)$ \\
\hline CNAi 8886 & $----------~$ & $\left(\mathrm{~kg} \mathrm{~kg}^{-1}\right)$ & ---------- & \\
CNAi 8569 & 23 & 105 & 56 & 37 \\
BRSGO Guará & 17 & 188 & 69 & 29 \\
BRS Jaburu & 21 & 222 & 123 & 29 \\
BRS Biguá & 16 & 114 & 64 & 26 \\
Média & 19 & 145 & 74 & 23 \\
\hline
\end{tabular}

(1)EA: eficiência agronômica; EF: eficiência fisiológica; EAF: eficiência agrofisiológica; ER: eficiência de recuperação. 
valor médio de $63 \mathrm{~kg}$ de grãos de arroz, produzidos com a acumulação de $1 \mathrm{~kg}$ de $\mathrm{N}$ na parte aérea e nos grãos. A eficiência de recuperação variou de 23 a $37 \%$, entre os genótipos, com valor médio de $29 \%$. Fageria et al. (2003a) relataram que a eficiência de utilização do N, pela cultura do arroz irrigado, é baixa, em conseqüência das perdas por volatilização, imobilização, lixiviação e desnitrificação. A maioria dos trabalhos realizados mostra que a eficiência de recuperação de $\mathrm{N}$, na cultura do arroz irrigado, situase entre 20 e 40\% (De Data et al., 1988; Schnier, 1994; Bronson et al., 2000).

\section{Conclusões}

1. Há efeito significativo e quadrático da aplicação de nitrogênio na produtividade de grãos.

2. A contribuição dos componentes de produção das plantas à produtividade de grãos é decrescente, na seguinte ordem: número de panículas > índice de colheita de grãos > massa de 1.000 grãos.

3. A eficiência do uso do nitrogênio varia de acordo com os genótipos e o tipo de eficiência calculada; em média, a eficiência de recuperação é baixa.

4. A menor esterilidade de espiguetas, nas maiores doses de nitrogênio, é característica importante no aumento da produtividade e apresenta comportamento diferenciado entre genótipos.

\section{Referências}

BRONSON, K.F.; HUSSAIN, F.; PASUQUIN, E.; LADHA, J.K. Use of ${ }^{15} \mathrm{~N}$-labeled soil in measuring nitrogen fertilizer recovery efficiency in transplanted rice. Soil Science Society of America Journal, v.64, p.235-239, 2000.

DE DATTA, S.K.; BURESH, R.J.; SAMSON, M.I.; KAI-RONG, W. Nitrogen use efficiency and nitrogen-15 balance in broadcastseeded flooded and transplanted rice. Soil Science Society of America Journal, v.52, p.849-855, 1988.

DOBERMANN, A.; DAWE, D.; ROETTER, R.P.; CASSMAN, K.G. Reversal of rice yield decline in a long-term continuous cropping experiment. Agronomy Journal, v.92, p.633-643, 2000.

EMBRAPA. Centro Nacional de Pesquisa de Solos. Sistema brasileiro de classificação de solos. Brasília: Embrapa-SPI; Rio de Janeiro: Embrapa-CNPS, 1999. 412p.

EMBRAPA. Serviço Nacional de Levantamento e Conservação de Solos. Manual de métodos de análise de solo. 2.ed. Rio de Janeiro: Embrapa-CNPS, 1997. 212p.
FAGERIA, N.K.; BALIGAR, V.C. Enhancing nitrogen use efficiency in crop plants. Advances in Agronomy, v. 88, p.97185, 2005.

FAGERIA, N.K.; BALIGAR, V.C. Lowland rice response to nitrogen fertilization. Communications in Soil Science and Plant Analysis, v.32, p.1405-1429, 2001.

FAGERIA, N.K.; BALIGAR, V.C.; CLARK, R.B. Physiology of crop production. New York: Haworth Press, 2006. 345p.

FAGERIA, N.K.; SLATON, N.A.; BALIGAR, V.C. Nutrient management for improving lowland rice productivity and sustainability. Advances in Agronomy, v.80, p.63-152, 2003 a.

FAGERIA, N.K.; STONE, L.F.; SANTOS, A.B. dos. Manejo da fertilidade do solo para o arroz irrigado. Santo Antônio de Goiás: Embrapa Arroz e Feijão, 2003b. 250p.

KINIRY, J.R.; McCAULEY, G.; XIE, Y.; ARNOLD, J.G. Rice parameters describing crop performance of four U.S. cultivars. Agronomy Journal, v.93, p.1354-1361, 2001.

MAE, T. Physiological nitrogen efficiency in rice: nitrogen utilization, photosynthesis, and yield potential. In: ANDO, T.; FUJITA, K.; MAE, T.; MATSUMOTO, H.; MORI, S.; SEKIYA, J. (Ed.). Plant nutrition for sustainable food production and environment. Dordrecht: Kluwer, 1997. p.51-60.

MARIOT, C.H.P.; SILVA, P.R.F. da; MENEZES, V.G.; TEICHMANN, L.L. Resposta de duas cultivares de arroz irrigado à densidade de semeadura e à adubação nitrogenada. Pesquisa Agropecuária Brasileira, v.38, p.233-241, 2003.

ROBERTS, S.R.; HILL, J.E.; BRANDON, D.M.; MILLER, B.C.; SCARDACI, S.C.; WICK, C.M.; WILLIAMS, J.F. Biological yield and harvest index in rice: nitrogen response of tall and semidwarf cultivars. Journal of Production Agriculture, v.6, p.585-588, 1993.

SCHNIER, H.F. Nitrogen-15 recovery fraction in flooded tropical rice as affected by added nitrogen interaction. European Journal of Agronomy, v.3, p.161-167, 1994.

SINGH, U.; LADHA, J.K.; CASTILLO, E.G.; PUNZALAN, G.; TIROL-PADRE, A.; DUQUEZA, M. Genotypic variation in nitrogen use efficiency in medium- and long-duration rice. Field Crops Research, v.58, p.35-53, 1998.

TEM BERGE, H.F.M.; RIETHOVEN, J.J.M. Application of a simple rice nitrogen model. In: ANDO, T.; FUJITA, K.; MAE, T.; MATSUMOTO, H.; MORI, S.; SEKIYA, J. (Ed.). Plant nutrition for sustainable food production and environment. Dordrecht: Kluwer, 1997. p.793-798.

VAHL, L.C. Fertilidade de solos de várzea. In: GOMES, A. da S.; PAUlETTO, E.A. (Ed.). Manejo de solo e da água em áreas de várzeas. Pelotas: Embrapa Clima Temperado, 1999. p.119-162.

YOSHIDA, S. Fundamentals of rice crop science. Los Baños: IRRI, 1981. 269p. 